\title{
Desenvolvimento e avaliação de um secador solar para grãos, associado a silo subterrâneo
}

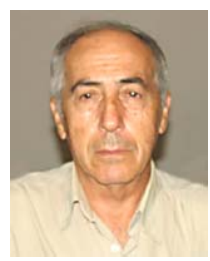

\author{
Carlos A. da S. Braga ${ }^{1}$, Cláudio A . Moreira² ${ }^{2}$ Afonso Peche Filho², José A.Bernardi², \\ Roberto da C. Mello², Moises Storino ${ }^{2} \&$ Antonio C. L. Lino ${ }^{2}$ \\ 1 In memoriam \\ 2 Centro de Engenharia e Automação/Instituto Agronômico de Campinas. E-mail: camoreira@iac.sp.gov.br \\ Protocolo 036 - 24/2/2003 - Aprovado em 20/20/2005

\begin{abstract}
Resumo: Um secador com aquecimento solar, tipo barcaça, com sistema mecânico de descarregamento, foi testado na secagem de grãos de feijão (Phaseolus vulgaris, L.). Em comparação com o sistema tradicional (secagem em terreiro), foram alcançadas reduções de: $83 \%$, no tempo de secagem; $76 \%$ na área necessária à operação e $95 \%$ no tempo de descarregamento do secador e enchimento do silo respectivo.
\end{abstract}

Palavras-chave: feijão, secador, aquecimento solar

\section{Development and evaluation of a solar drier for grains associated to underground bin}

\begin{abstract}
A batch-type, solar-heated air drier with mechanical system of unloading was tested in drying edible beans (Phaseolus vulgaris, L.). Reductions in drying time and area, reached 83 and $76 \%$, respectively, as compared with the natural drying process. A hand-driven mechanical unloading system incorporated allows $95 \%$ reduction in unloading time.
\end{abstract}

Key words: edible beans, drier, solar hating

\section{INTRODUÇÃO}

O Brasil, além de maior produtor, é também o maior consumidor de feijão, visto que este produto representa não apenas valor econômico significativo para o País mas, acima de tudo, alimento básico de grande alcance social, principalmente das classes menos favorecidas.

A secagem do feijão pode ocorrer no campo, ainda na planta, em terreiro ou artificialmente, em secadores mecânicos, ao passo em que a armazenagem tem lugar em paiol, galpão e em grandes silos, no caso de lavouras mais extensas.

Segundo Sathler et ali, (1980), citando Hukill (1974), o teor de umidade contida nos grãos afeta a sua colheita, a secagem, a armazenagem e a germinação, havendo para os vários processos, valores ideais que devem ser observados.

De acordo com Silva et al., (1975), para fins comerciais, normalmente os agricultores efetuam a colheita do feijão quando as vagens estão secas e parte das folhas caída, correlacionando este fato com um teor de umidade da semente propício ao beneficiamento e ao armazenamento do produto.

Em geral, esse procedimento compromete a qualidade, devido ao longo período de secagem após a maturação em que as vagens permanecem na planta submetidas a condições climáticas adversas, e ao sistema de armazenamento inadequado na propriedade.

A secagem na planta ou no terreiro, principalmente nas "culturas das águas", além de estar sujeita a perdas provocadas por insetos, fungos, pássaros, roedores e por agentes meteorológicos adversos, é lenta, exigindo um tempo maior do que no processo artificial.

Um produto de melhor qualidade pode ser obtido realizandose a colheita ao se atingir a maturação fisiológica, ocasião em que os grãos apresentando teor de umidade mais elevado do que o recomendado para conservação a longo prazo torna a secagem, seja em terreiro ou artificial, imprescindível.

Sathler et al. (1980) recomendam, em trabalhos sobre a conservação do feijão, a secagem rápida dos grãos, além do armazenamento do produto em silos adequados.

Secadores e silos de grande capacidade, além dos custos elevados, do alto consumo de energia e de temperaturas de operação mais altas, quando operados inadequadamente submetem o produto a condições severas de secagem e de armazenagem, comprometendo sua qualidade final (Rossi \& Roa, 1980).

Silva (1982) desenvolveu um secador para feijão em rama tendo como fonte de calor, fornalha a lenha por fogo direto. 
Moreira et al. (1995) construíram secador para grãos, com ventilação forçada do ar ambiente, aquecido por fornalha a lenha, de fogo direto, fluxo descendente.

Um secador protótipo de pequena capacidade para secagem de feijão em vagem, foi desenvolvido no Departamento de Engenharia Agrícola da Universidade Federal de Viçosa por Araújo (1983), usando resistência elétrica para aquecimento do ar.

Com relação à armazenagem na propriedade agrícola, já se dispõe de tecnologia alternativa simples, de baixo custo, como os sistemas herméticos, normalmente subterrâneos, desenvolvidos por Hyde \& Burrel (1973), os mais utilizados.

O elemento básico deste sistema é a unidade de silo subterrâneo, revestido de filme de polietileno, de baixa densidade $(0,30 \mathrm{~mm}$ de espessura), de fácil instalação na propriedade

Constata-se que a adoção desta tecnologia por parte de nossos agricultores tem ocorrido em pequena escala, devido a fatores limitantes relacionados com a secagem prévia dos grãos e ao seu carregamento nos silos, os quais, realizados manualmente, oneram custos, tornando a operação demorada, desconfortável e desgastante.

Com este trabalho objetivaram-se o desenvolvimento e a avaliação de modelo de secador associado a silo subterrâneo, comparando os resultados desse sistema com os do método convencional (secagem em terreiro), como tentativa de viabilizar um processo alternativo de secagem e armazenagem para a pequena propriedade.

\section{MATERIAL E MÉTODOS}

Um protótipo de secador, com um sistema de descarregamento mecânico, de acionamento manual, com capacidade de 1,5 t de feijão em grão, foi projetado e construído na Divisão de Engenharia Agrícola do Instituto Agronômico de Campinas.

Compõem o sistema: o secador propriamente dito, um coletor de energia solar, um ventilador para forçar a circulação do ar aquecido, além de silos subterrâneos, para armazenamento do produto seco.

O corpo, formando uma caixa retangular de $3,00 \times 2,20 \mathrm{x}$ $0,40 \mathrm{~m}$ (comprimento $\mathrm{x}$ largura $\mathrm{x}$ altura), é constituído de duas partes móveis e articuladas na parte mediana, o que permite o seu basculamento para descarga dos grãos (Figura 1 A, B e C).

A estrutura, construída com sarrafos, e revestida de chapa de madeira compensada, comporta uma câmara de secagem cujo fundo apresenta furos compatíveis com o tamanho dos grãos e, abaixo dela, uma outra câmara (plenum) através da qual se promove a distribuição uniforme do fluxo de ar aquecido, impulsionado por um ventilador através da massa (Figura 2A e B).

O corpo do secador é montado sobre chassi, construído com caibros de madeira apoiado sobre 4 rodas de ferro. No chassi é fixado um cavalete de madeira, para suporte da talha manual e também para apoio da cobertura removível de material plástico transparente.

A operacionalização do sistema envolve a secagem pela circulação forçada do ar aquecido, seguida da descarga, por

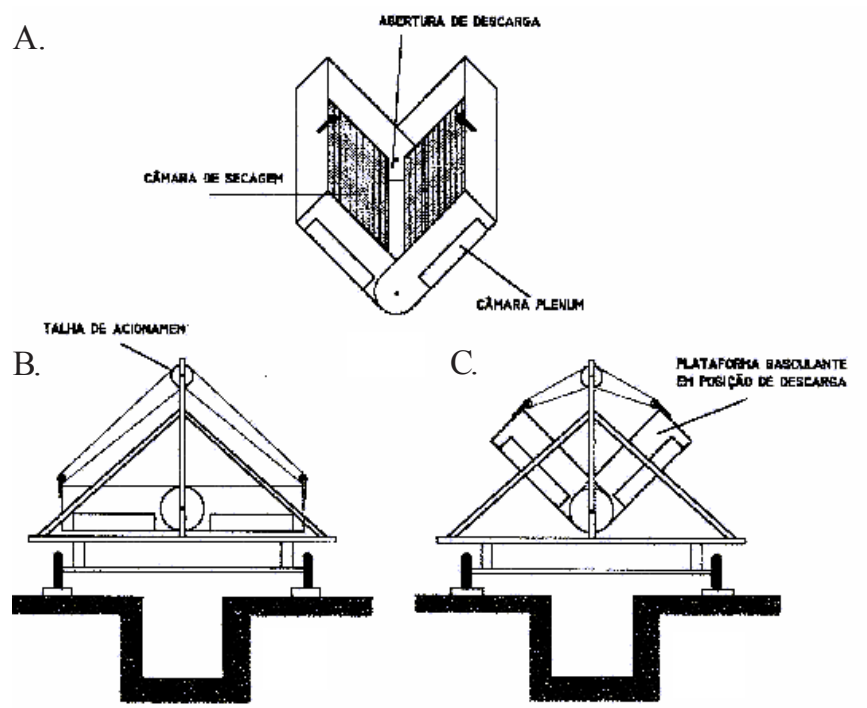

Figura 1. Vista esquemática do secador: (A) condição de carga; (B) condição de secagem; (C) condição de descarga
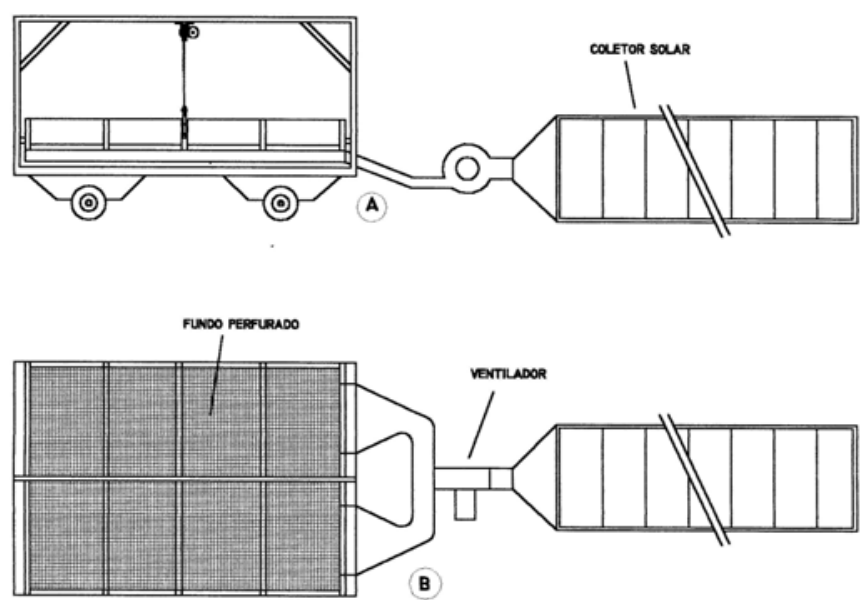

Figura 2. Esquema do acoplamento secador-ventilador e coletor solar

gravidade, do produto seco na unidade de armazenamento ou seja no silo subterrâneo revestido com filme de polietileno, situado em plano inferior.

Nesta operação, as seções móveis basculantes do secador são erguidas pelas bordas laterais por meio de talha de acionamento manual, permitindo a saída livre dos grãos depositados na câmara de secagem.

O sistema mecânico de descarga reduz significativamente o esforço do operador, permitindo que as bordas das duas seções sejam erguidas com velocidade média de $0,5 \mathrm{~m} \mathrm{~min}^{-1}$ até a altura máxima de aproximadamente $1 \mathrm{~m}$.

O coletor solar utilizado, do tipo plano, não convencional, configuração semicilíndrica, apresenta a superfície absorvedora de energia solar, com área de $24 \mathrm{~m}^{2}$, orientada para o norte geográfico, e inclinada de $23^{\circ}$ (latitude local) em relação ao plano horizontal, visando à máxima eficiência na absorção e, conseqüentemente, na produção de calor.

Instalaram-se 4 unidades de silos subterrâneos revestidos com polietileno, com capacidade de armazenagem de $2 \mathrm{t}$ cada uma. 
A secagem convencional, sistema mais empregado nas propriedades produtoras e adotado como testemunha, foi realizada em terreiro revestido de tijolos comuns, com área de $66,7 \mathrm{~m}^{2}$.

A instrumentação utilizada incluiu: tubos de Pitot; bússola; determinador de umidade de grãos; piranômetro integrador digital; anemômetro digital; termômetros de mercúrio; termohigrógrafo, higrômetro, termômetros de bulbo seco e úmido e pirômetro digital.

O desempenho do sistema proposto foi determinado segundo dois aspectos distintos: o primeiro ligado à secagem propriamente dita e o segundo, ao manejo do produto póssecagem ou seja descarregamento do secador/carregamento do silo subterrâneo.

Para fins comparativos, no sistema adotado como testemunha foram objetos de observação: a) secagem propriamente dita e, b) carregamento dos silos transportando o produto em carrinhos manuais.

\section{Caracterização dos ensaios realizados:}

1. Com secador protótipo: foram secadas 3,0 t. de feijão em duas repetições de 1,5 t cada, observando-se um intervalo de uma semana entre elas.

$\mathrm{O}$ produto, que apresentou no primeiro e no segundo ensaios, 25 e $22 \%$ de umidade inicial, respectivamente, foi secado até a umidade final de $12 \%$ e, em seguida, armazenado diretamente no silo.

A movimentação forçada de ar quente $\left(30 \mathrm{~m}^{3} \min ^{-1} \mathrm{t}^{-1}\right)$, foi dimensionada para a secagem em camada com espessura de $0,35 \mathrm{~m}$

Durante o processo foram retiradas, a cada 4 horas, amostras de aproximadamente $100 \mathrm{~g}$, em duas alturas na massa de grãos, para determinação da marcha da secagem.

Foram levantados, ainda dados de: radiação solar diária incidente no plano coletor; temperaturas e umidades relativa do ar na saída do coletor e na entrada do secador; fluxos de ar na saída do coletor e na entrada do secador (câmara plenum).

$\mathrm{O}$ ventilador operou por oito horas, diariamente, durante a secagem.
2. Ensaio da secagem em terreiro: (testemunha) - envolveu duas repetições com 1,5 t. cada uma, distribuídas em camada de $0,03 \mathrm{~m}$, apresentando o produto 25 e $22 \%$ de umidade (base úmida), respectivamente, no início da operação.

Durante os ensaios, a cada hora, foram feitas leituras de temperatura, umidade relativa do ar, radiação solar incidente no plano do terreiro e velocidade do vento.

Amostras de feijão $(100 \mathrm{~g})$ foram retiradas a cada $4 \mathrm{~h}$, para determinação da curva de secagem.

Para uniformização da secagem, o produto foi revolvido a cada $4 \mathrm{~h}$, até a umidade final de $12 \%$.

3 e 4. Ensaio do carregamento dos silos: mecanizado e manual: o produto secado artificialmente foi descarregado diretamente no silo (ao passo em que o secado em terreiro foi transportado em carrinho-de-mão até aquele local, afastado cerca de $40 \mathrm{~m}$. (Ensaio 4)

Nesse ensaio foram obtidos dados relativos aos seguintes parâmetros:

- massa de produto $(\mathrm{kg})$

- capacidade do silo $(\mathrm{kg})$

- mão-de-obra para operacionalização ( $\mathrm{n}^{0}$ de operários)

- mão-de-obra para transporte ( ${ }^{\circ}$ de operários)

- fluxo de carga e descarga $\left(\mathrm{kg} \mathrm{min}{ }^{-1}\right)$

- tempo de carregamento total do silo (min.)

\section{RESULTADOS E DISCUSSÃO}

A Tabela 1 apresenta, os valores médios observados na secagem artificial (Ensaio 1) e, nas duas últimas e convencional (Ensaio 2).

Observou-se redução média de $14,6 \%$ no tempo de secagem artificial devido à maior quantidade de energia útil disponível ao processo e redução de $90,3 \%$ com relação à área ocupada pelo do produto. A eficiência térmica alcançou $71 \%$, valor significativo quando comparado com os $15 \%$ obtidos em média no processo convencional.

Os resultados experimentais relacionados com a fonte de calor (energia solar incidente, temperatura e umidade relativa ambientes) são apresentados na Tabela 1.

Tabela 1. Resultados de secagem no secador protótipo e no terreiro

\begin{tabular}{lccccc}
\hline \multicolumn{1}{c}{ Parâmetros operacionais } & \multicolumn{2}{c}{ Ensaio 1 (Secador) } & & \multicolumn{2}{c}{ Ensaio 2 (Terreiro) } \\
\cline { 2 - 3 } \cline { 5 - 6 } & $\mathrm{a}$ & $\mathrm{b}$ & & $\mathrm{a}$ & $\mathrm{b}$ \\
\hline Tempo de secagem diária $(\mathrm{h})$ & 8 & 6,4 & 6,4 & 8 & 8 \\
Área de secagem $\left(\mathrm{m}^{2}\right)$ & 1500 & 1500 & & 1500 & 66,0 \\
Massa de feijão úmido $(\mathrm{kg})$ & 0,25 & 0,25 & 0,03 & 1500 \\
Espessura da camada $(\mathrm{m})$ & 220 & 170 & 222 & 0,03 \\
Massa de água evaporada $(\mathrm{kg})$ & $650480(155400)$ & $499280(119280)$ & $650480(155400)$ & $499280(119280)$ \\
Energia p/ evaporação da água $(\mathrm{kJ})(\mathrm{kcal})$ & $1362(325,3)$ & $1378(329,2)$ & $304(72,7)$ & $326(77,8)$ \\
Energia útil disponível $\left(\mathrm{kJ} \mathrm{m}^{-2} \mathrm{~h}^{-1}\right)\left(\mathrm{kcal} \mathrm{m}^{-2} \mathrm{~h}^{-1}\right)$ & 28 & 20 & 32 & 24 \\
Tempo total de secagem $(\mathrm{h})$ & $2549(609)$ & $2771(662)$ & $2369(566)$ & $2549(609)$ \\
Energia solar incidente $\left(\mathrm{kJ} \mathrm{m} \mathrm{m}^{-2} \mathrm{~h}^{-1}\right)\left(\mathrm{kcal} \mathrm{m}^{-2} \mathrm{~h}^{-1}\right)$ & 25,0 & 25,9 & 25,2 & 25,9 \\
Temperatura ambiente $\left({ }^{0} \mathrm{C}\right)$ & 36,9 & 37,2 & 30,9 & 32,2 \\
Temperatura ar de secagem $\left({ }^{0} \mathrm{C}\right)$ & 78,6 & 79,0 & 78,6 & 79,0 \\
Umidade relativa ar ambiente $(\%)$ & 52,6 & 50,8 & 25,7 & 28,4 \\
Redução umidade relativa do ar $(\%)$ & 30 & 30 & - & - \\
Vazão de ar de secagem $\left(\mathrm{m}^{3} \mathrm{~min}^{-1} \mathrm{~h}^{-1}\right)$ & & &
\end{tabular}


Foram constatadas: diferenças significativas entre a quantidade de energia solar disponibilizada pelo coletor para aquecimento do ar e a absorvida pelos grãos, diretamente, no terreiro, motivadas pela inclinação da superfície coletora em relação à órbita solar aparente no valor de $23^{\circ}$ ( latitude local);

Observou-se, ainda, razoável diferença entre os teores de umidade relativa natural do ar no ambiente externo e os observados na saída do coletor, aumentando o potencial de secagem do secador.

A Figura 3 mostra os resultados da variação do teor de umidade nos grãos localizados a 17 e $35 \mathrm{~cm}$ a partir do fundo perfurado do secador, observando-se uma diferença de cerca de $2 \%$ entre os valores médios, exceto no início e nas últimas horas de secagem, quando tende a $0 \%$, na medida em que a umidade final nos dois ensaios se aproxima de $12 \%$.

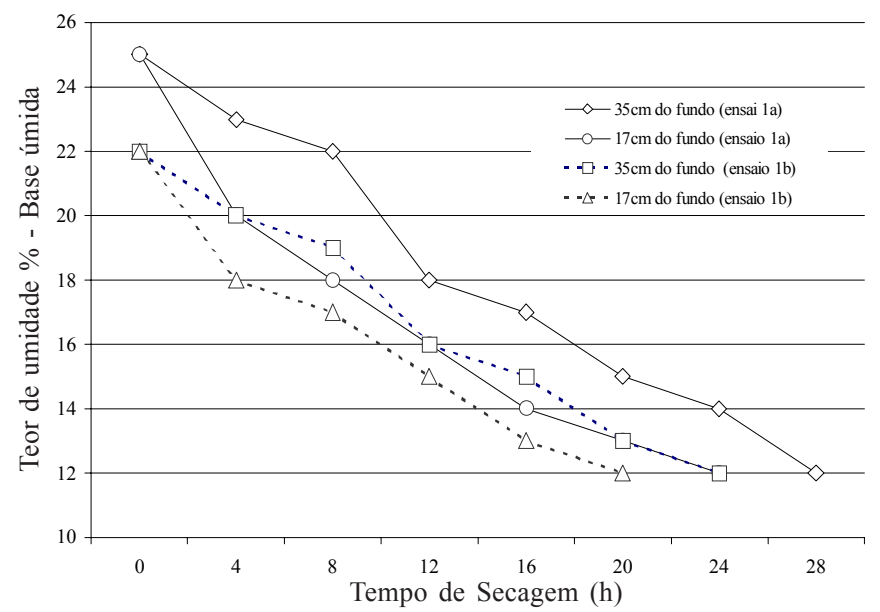

Figura 3: Redução do teor de umidade em base úmida (\%) em função do tempo (no secador)

$\mathrm{Na}$ secagem em terreiro (Ensaio 2), devido à reduzida espessura da camada de produto $(0,03 \mathrm{~m})$, observou-se durante o período diurno $(8-17 \mathrm{~h})$ redução uniforme na umidade e, no noturno, uma ligeira reumidificação devida ao aumento da umidade relativa do ar, causada pelo abaixamento da temperatura ambiente. (Figura 4).

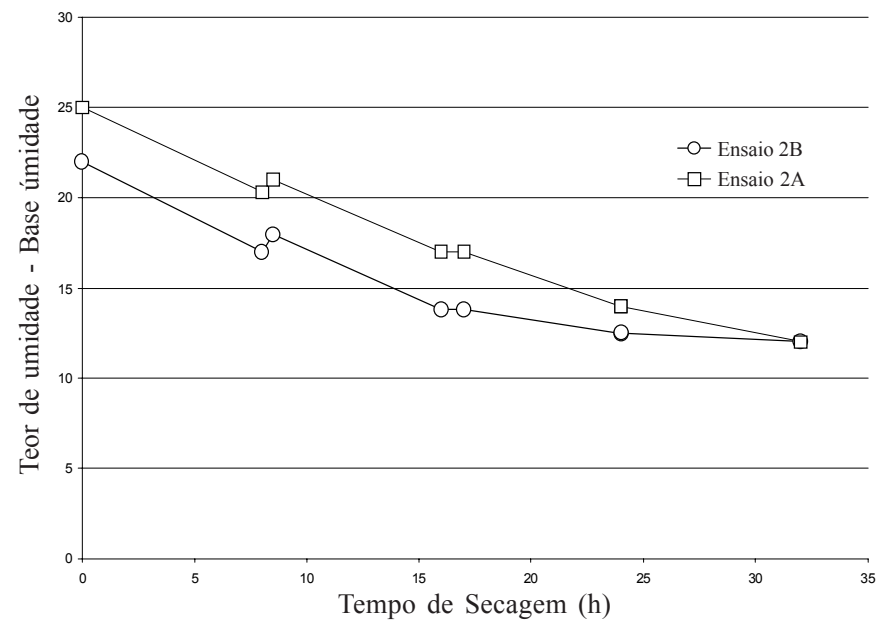

Figura 4. Redução do teor de umidade em base úmida (\%) função do tempo (no terreiro)
O sistema basculante de descarga apresentou taxas médias de de 226 e $222 \mathrm{~kg} \mathrm{~min}^{-1}$, permitindo o enchimento dos silos em 5 e 6 min, o que implica numa redução de tempo de $97,4 \%$ em comparação com o carregamento manual.

As Figuras 5 e 6 apresentam as curvas de radiação solar e de temperaturas de secagem em secador e no terreiro (valores médios horários).

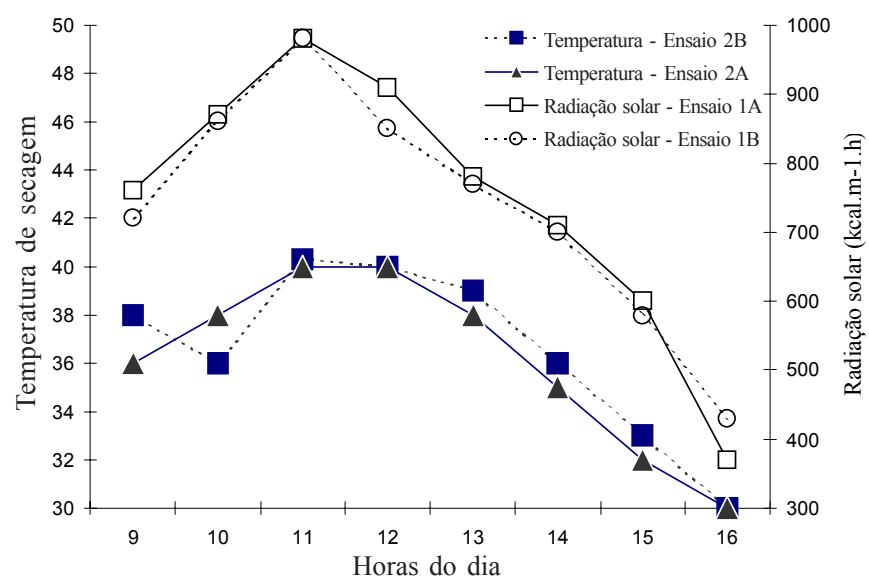

Figura 5. Temperatura do ar de secagem $\left({ }^{\circ} \mathrm{C}\right)$ e radiação solar incidente $\left(\mathrm{kcal} \mathrm{m}^{-1} \mathrm{~h}\right)$ no plano do coletor

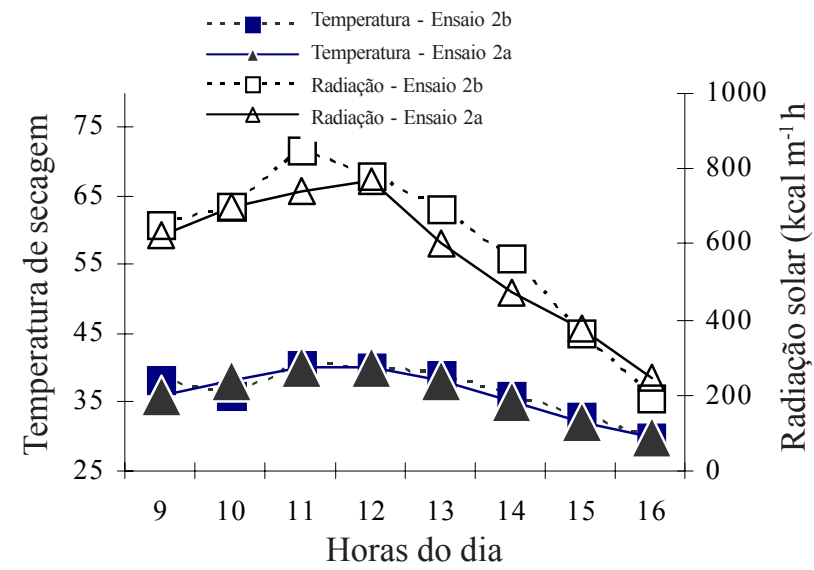

Figura 6. Radiação solar $\left(\mathrm{kcal} \mathrm{m}^{-1} \mathrm{~h}\right)$ incidente no terreiro e temperatura de secagem $\left({ }^{\circ} \mathrm{C}\right)$

\section{CONCLUSÕES}

1. O secador apresentou alto rendimento tanto na secagem, com eficiência térmica de $71 \%$, como na armazenagem subterrânea, com fluxos de carga de 226 e $222 \mathrm{~kg} \mathrm{~min}^{-1}$, reduzindo em $97,4 \%$ o tempo necessário a essa operação.

2. Os resultados obtidos demonstram a viabilidade técnica e econômica do sistema integrado de secagem-armazenagem para pequenas e médias propriedades rurais;

3. A facilidade de construção e de operacionalização viabilizam a adoção do sistema pelos produtores.

\section{AGRADECIMENTOS}

Os autores agradecem ao Técnico de Apoio à Pesquisa, Varli José Dorighello e à Agente de Apoio à Pesquisa, Elaine Sanches Zaccharias pela colaboração. 


\section{LITERATURA CITADA}

Araújo, E.F.. Influência de secagem e debulha das vagens na germinação e no vigor de sementes de feijão (Phaseolus vulgaris, L). UFV, 1983, 74p. Dissertação Mestrado

Hukill, W.V.. Drying of grain, In: Cristensen C.M., (ed). Storage of cereal grain and their products. St. Paul: 1974. p.481580.

Hyde, M.B.; Burrel.. Some recent aspects of grain storage tecnology. In: Sinha, R.N.; Muir, W.E. (ed) Grain storage Part of a system. Wesport: AVI, 1973,. 313-341p.

Moreira, C.A.; Lasca, D.H.C.; Bernardi, J. A.. Secador estático de pequena capacidade para amendoim. In: Anais do Encontro Nacional de Secagem, 5. Anais... Lavras: UFLA, junho, 1995.6p.
Rossi, S.J.; Roa, G.. Secagem e armazenamento de produtos agropecuários com uso de energia solar e ar natural. Campinas: ACIESP. 1990. 295p. Publicação ACIESP nº 22.

Sathler, M.G.B.; Pinheiro Filho, J.B.; Hara, T.; Fortes, M.; Sediyama, G.C. Condé, A. R.. Secagem de feijão (Phaseolus vulgaris $\mathrm{L}$.) em camadas finais, a baixas temperaturas e seus efeitos na germinação das sementes. Revista Brasileira de Armazenamento. Viçosa,v.5, n.1, 43-9p, 1980.

Silva, C.M.; Vieira, C.; Sedyama, C.S.. Determinação da época adequada de colheita de feijão (Phaseolus vulgaris L.) com base na qualidade fisiológica das sementes. Sementes.1220, 1975.

Silva, J.S.. Secagem de feijão em ramas. Informativo Agropecuário. Belo Horizonte, v.8, n.90, p.55-62, 1982. 